\title{
From Joint to Nuclear: Some Observations on the Changing Pattern of Family as a Social Institution
}

\author{
Arya Priya \\ Research Scholar; PhD (Sociology); \\ Centre for the Study of Social Systems (CSSS)/School of Social Sciences (SSS); \\ Jawaharlal Nehru University (JNU), New Delhi -110067
}

\begin{abstract}
The study of changes in the structure and composition of the family and the household has always occupied a center stage in sociological discourses. Since the onset of urbanization and modernization following the industrial revolution, families all across the world have undergone qualitative changes. The kinship based, extended or joint families have been increasingly replaced by nuclear households. This change has also brought fundamental alterations in the long-standing inter-personal relationships within the family - such as husbandwife relationship, parent-child relationship or sibling relationship. This paper intends to explore the thesis of the increasing nuclearisation of the family in all its dimensions - the factors responsible for it, the various theoretical formulations and sociological researches and the overall trajectory of family patterns in India in the post-independent India.
\end{abstract}

Keywords:functionalism, nuclear family, joint family, structural differentiation, developmental cycle.

\section{INTRODUCTION:}

Family, as far as its structure and composition is considered, is one of the most baffling social institutions to define. What is a nuclear family, what constitutes jointness, where to draw the line or are there really some dichotomous entities like nuclear or joint families - these are some of the issues that have constantly plagued the social scientists. Family has been variously defined by different sociologists and some form of consensus on the definitional aspect of the family still appears a remote possibility. However, the most commonly accepted definition of the nuclear family is that it consists of husband and wife with or without their unmarried children, whether biological or adopted [Abraham 2015:182]. The joint family, especially in India, is generally seen in terms of at least three generations of parents, their married children and grandchildren living together (lineal joint family) or brothers and their wives and children residing together (fraternal joint family) (Dube, 1955; Gore, 1968). ${ }^{1}$

\section{NUCLEARISATION THESIS - THEORIES AND RELATED DEBATE:}

The roots of nuclearisation theory of the family can be traced back to the industrial revolution when the process of modernization kicked-off. Many sociologists contend that industrialization, urbanization, spatial and social mobility, stress on individualism and rise in the education and status of women have led to fundamental changes in the family structure. It has moved from tradition-based extended structures to nuclear householdsAmong all the sociologists, Talcott Parsons' theoretical insights on family have attracted widest attention and deliberation. Parsons $(1954,1956)$ argues that modern industrial society has led to the growth of what he calls 'isolated nuclear family". This family is 'structurally isolated' as it does not form an integral part of the wider kinship group. Parsons theory of emergence of the isolated nuclear family can be seen in terms of his general theory of social evolution. The evolution of societies involves a process of structural differentiation. ${ }^{2}$ This means that many new social institutions emerge which specialize in fewer functions. Under these circumstances, many of the functions of the traditional family have been taken up by the new specialized institutions like schools, colleges, factories, hospitals etc. This has facilitated the emergence of nuclear families.Parsons was basically a functionalist and he argued that there is a functional relationship between the isolated nuclear family and the modern economic system. Nuclear families best meet the requirements of the industrial society. In modern societies with high division of labour, individuals with specialized skills are required to move to far-off places. Isolated nuclear family is geared for this kind of geographical mobility. Further, an individual's status in modern industrial society is primarily based on achievement criterion and on universalistic standards. This fits well with nuclear families. In a traditional kinship-bound family, a person's status is generally based on ascriptive criterion and on particularistic values. In modern industrial society, ascribed status might lead to conflict in the family and psychological strain on the individual. 
Because of the isolation of the nuclear family, the conjugal ${ }^{3}$ bonds are greatly strengthened. Spouses are heavily dependent on each other for emotional support. Parsons argues that stabilization of the adult personality is a major function of modern nuclear family. Nuclear family has another fundamental function i.e. socialization of the young children.

In the words of Parsons (1956: 3-19):

"The American family has, in the past generation or more, been undergoing a profound process of change.... What has been happening to the American family constitutes part of the process of differentiation. This process has involved reduction of the importance, in our society, of kinship units other than the nuclear family. It has also resulted in the transfer of a variety of functions from the nuclear family to other structures of the society... This means that the family has become a more specialized agency than before... On the basis of the kinship organization, this has led to the 'isolation' of the nuclear family....This isolation is manifested in the fact that the members of the nuclear family, consisting of parents and their dependent children, ordinarily occupy a separate dwelling not shared with members of the family of orientation of either spouse...This 'isolated nuclear family', besides being apt for modern industrial society, has two basic and irreducible functions...first, the primary socialization of the children....the second primary function of the family concerns regulation of balances in the personalities of the adult members of both sexes..."

Parsons' theory initiated a flurry of debates and sociological researches on family patterns. While some researchers corroborated his theory and found merit in his argument, others refuted his contentions. One of the most pioneering works is that of Goode (1963). Goode surveys the relationship between family structure and industrialization in various parts of the world. He endorses Parsons' view that rising industrialization is undermining extended family and larger kinship group. However, he does not regard industrialization as the only reason for the breakdown of extended family ties. The move to industrial family has been far more rapid than can be predicted from the degree of industrialization. Goode believes that it is the ideology of the nuclear family that has encouraged its spread, especially in the developing countries. This is because of the high prestige associated with western life-styles and ideas in many of these developing societies.

Goode also surveys family pattern among different social classes. He found that extended families are more common among the upper class families. Since members of the ruling classes and elites have an important influence on appointment to top jobs, the maintenance of family ties makes huge economic sense. In comparison, members of the working class have little to offer to their younger generations. As such, there is greater dispersal of the family members. Another important work is that of Peter Laslett (1972). He studied family size and composition in pre-industrial England. From 1564-1821, he found only $10 \%$ of households containing kin beyond the nuclear family. He found no evidence to support Parsons' view that the extended family was widespread in pre-industrial society and got transformed into nuclear families in modern times.

Parsons' argument of isolated nuclear family as functional in individualized industrial society has led to its own series of debates. In their highly celebrated work, Young and Willmot (1975) hold that nuclear family has proved to be functional in one respect. Due to strengthening of conjugal bonds and the employment and education of women, the power equation within the family has become more symmetrical. Women enjoy equal status as their husbands and equally participate in all decision-making processes. However, a contrary view on the functional aspect of the nuclear family is put forth by Leach (1967). He holds that in a nuclear family, there is a huge emotional demand on each other. He likened the family to an overloaded electric circuit. The demand made upon it is too great and often the fuse blows. The parents constantly fight; the children always rebel.

Any discussion on nuclear family would be incomplete if Marxian analysis is not invoked. Engels (1884/1972) holds that during primitive communism, there was no family and promiscuity prevailed. The monogamous nuclear family arose with the emergence of private property and state institutions. Emergence of private property required that it got passed to its legitimate heirs. Monogamous nuclear family arose to control female sexuality and ensure legitimate progeny. In the words of Engels:

"monogamous family is based on the supremacy of man, the express purpose being to produce children of undisputed paternity; such paternity is demanded because these children are later to come into their father's property as natural heirs". 4

\section{Indian Society - Indian sociologists on Nuclearisation of family:}

As far as Indian society is concerned, sociological researches have brought forth many fascinating results. It is extremely important to know that the Indian family is highly diversified. Keeping in view this diversity, a uniform family pattern is very difficult to expect throughout India. There are variations in family patterns not only regionally, but also on the basis of caste, religion and on rural-urban basis. And so, it is not surprising that the sociological researches on family patterns in India are as diversified as the diversity of India itself.

Kolenda (1967: 147-228) brings out the following patterns of family in India: 
- Joint family is more characteristic of higher twice-born castes, while least characteristic among the lower castes and the scheduled castes.

- Regional differences exist in the prevalence of joint family. North India, especially the Gangetic Plain shows higher incidences of joint families than Central or South India like Madhya Pradesh, Mahararashtra, Tamil Nadu or Andhra Pradesh.

- There is a difference in the customary time of the break-up of joint families in various groups and places in India.

As far as rural areas are concerned, most of the studies show that traditional joint family is predominant among the upper castes like the landed gentry and the priestly class. Nuclear family is more prevalent among the lower castes. Cohn (1961) in his study of Chamars of Senapur (UP) tries to explain as to why the achievement of joint family is so difficult among the scheduled castes. This is due to several factors such as a) Demographic factor: with low life-expectancy among the lower castes, there is less chance of three generations existing at the same time, b) Spatial mobility: Movement of individuals from one place to another in search of better economic opportunities also makes joint families difficult and c) Role of women: women in these families have always worked since pre-industrial times due to financial constraints. The pronounced status of women in these families and strong conjugal bonds has critical role to play in the weakening of the lineal or fraternal bonds.

As regards urban centers, many sociological studies do indicate that as a consequence of the surge in industrialization and urbanization since recent past, the number of nuclear households is increasing at an unprecedented rate. However, Kapadia (1958) maintains that families which have migrated to cities still retain their joint family bonds in their native villages or towns. These families retain their, what he calls, 'Joint Family Ethic'. This is evident from the physical presence of the relatives at the time of certain events like birth, marriage, death, illness etc.

Srinivas (1969) also contends that joint family is not breaking down as such in urban areas. He says:

"Even if figures of urban areas show a dwindling in the size of the family, it does not mean that the joint family system is breaking down. Urban families are frequently not autonomous entities but limbs of bigger families situated elsewhere. Any crisis in the parent or offspring family will be faced as a common problem. Weddings, funerals and other ceremonies are usually celebrated in the 'parent' household. There is occasionally transference of persons from one family to the other" (Srinivas, 1969:72)

In similar vein, Shah (1998:6-7) argues:

"It would be a mistake to consider the entire urban society as moving against the joint household norm. The business class, from the richest industrialists to petty shopkeepers, is steeped in joint family culture. So also is the lower middle class composed of the clerks, school teachers, and such others. The proletariat composed of industrial and other workers appear to be oriented towards the nuclear family due to their being migrants from villages, but are in fact not so oriented. Even the professional class, which could be considered as having come under the maximum impact of the ideology of the nuclear family and individualism, is also not uniform in its culture."

Some sociologists such as Desai (1964), Madan (1965) and Dube (1955) have tried to overcome the notion of dichotomous existence of family as nuclear or joint by adopting the "development cycle" approach to study family changes in India. According to them, family is to be seen as a process that undergoes cyclical changes due to the phenomenon of fission and fusion. Joint and nuclear families are to be seen as two stages on the continuum in a cycle. Family structure keeps changing in a cyclical fashion - 'expanding' from nuclear to joint with marriage and birth and 'depleting' from joint to nuclear with death and partition. Overall, it can be argued that in contemporary India, family is undergoing adaptive and reconciliatory changes. The joint family ethic or world-view is still strong in India.

\section{CONCLUSION:}

Family is a very fluid social institution and in the process of constant change. The modern family or, rather the post-modern family is also witnessing several new forms of it cropping up. Post-modernity is witnessing the emergence of same-sex couples, cohabitation or live-in relations, single parent households and a large chunk of divorced living alone or with their children. Further, though nuclear family does play a vital role in enhancing the status and power of women within the family, it is not free from vices. It has its own share of problems as is evident from too much emotional dependence of its members on each other, constant bickering and squabbles among the spouses, rising divorce rates and the increasing negligence of the old-age people. With new dimensions of relationships and marriages coming up, the traditional idea of family has come under serious question. Family, all over the world, is facing the heat - not only with regard to its long-standing definition and conception but also with regard to its very existence as a social institution. 


\section{NOTES}

1) However, the variation in the typology of family is so large that Pauline Kolenda (1968: 346-348) identifies 12 types of families in India depending on their nuclearity or jointness. They are: 1) nuclear 2) supplemented nuclear 3) subnuclear 4) single-person 5) supplemented subnuclear6) collateral joint 7) supplemented collateral joint 8) lineal joint 9) supplemented lineal joint 10) lineal-collateral joint 11) supplemented linealcollateral joint and 12) others. These types are based on certain basic terms with distinctive connotations - a) the nuclear family means a couple with or without unmarried children b) a subnuclear family consists of either of the parents and unmarried children, or siblings c) A family is joint if it includes two or more related couples d) in a lineal joint family the married couples are linked by a lineal link, in a collateral joint family by a sibling link, and in a lineal-collateral joint family by lineal and collateral links e) the unmarried, widowed or divorced relatives who are not children of any of the married couples in the family supplements the family, whether joint, nuclear or subnuclear and f) 'Other' is a residual category.

2)A notion with a long history in sociology, differentiation in mainly used in theories of social change. Structural differentiation refers to the process whereby sets of social activities performed by one social institution split up between different institutions. Differentiation represents an increasing specialization of the parts of a society, giving greater heterogeneity within the society. For example, whereas the family once had reproductive, economic and educational functions, in modern societies, specialized institutions of work and education have developed outside the family (Abercrombie et al. 2006: 109).

3) The term conjugal refers to the relationship between marriage partners, or between a man and a women living together. The tasks typically taken up by husband and wife in the household are referred to as conjugal roles (Abercrombie et al. 2006: 77).

4)http://www.marxist.org/archive/marx/works/1884/origin-family/

\section{REFERENCES:}

[1] Abercrombie, N, S. Hill and B. Truner. (2006). Penguin dictionary of sociology. London:Penguin.

[2] Abraham, Francis. (2015). Contemporary sociology ( $2^{\text {nd }}$ ed.). New Delhi: Oxford University Press.

[3] Cohn, B. S. (1961). Chamar family in a north Indian village: A structural contingent. The Economic Weekly XIII; 1051-55.

[4] Desai, I.P. (1964). Some aspects of family in Mahua. Bombay. Asia Publishing House.

[5] Dube, S.C. (1955). Indian village. London: Routledge.

[6] Engels, F. (1884) [1972]. The origin of the family, private property andthe state. London: Lawrence and Wishart.

[7] Goode, W.J. (1963). World revolution and family patterns. New York: Free Press.

[8] Gore, M.S. (1968). Urbanization and family change. Bombay: Popular Prakashan.

[9] Kapadia, K.M. (1958). marriage and family in India. Bombay: Oxford University Press.

[10] Kolenda, Pauline. (1967). Regional differences in Indian family structure. In Robert Crane (Eds.) Regions and regionalism in South Asian studies (monograph 5, Duke University programme in comparative studies of Southern Asia).

[11] Kolenda, Pauline. (1968). Region, caste and family structure: A comparative study of theIndian joint family. In Milton Singer and Bernard Cohn (Eds.). Structure and change inIndian society(pp 339-396). New York: Wenner-Green Foundation.

[12] Laslett, P (Ed.) (1972). Household and family in past time. New York: Cambridge University Press.

[13] Leach, E.R. (1967). A Runaway World ? London: BBC Publications.

[14] Madan, T.N. (1965). Family and kinship: A study of the pandits of rural Kashmir. Bombay: Asia Publishing House.

[15] Shah, A.M. (1998). The family in India: Critical essays. New Delhi. Orient Longman.

[16] Srinivas, M.N. (1969). India: Social structure. New Delhi: Publications Division.

[17] Parsons, Talcott. (1954). Essays in sociological theory. New York: Free Press.

[18] Parsons, Talcott. (1956). family: socialization and interaction process. London: Routledge.

[19] Young, M and P. Wilmott. (1975). The symmetrical family. London: Penguin 